\title{
Total Femoral Prosthesis in Malignant Bone Tumours: A Case Series
}

\author{
Kishore B Reddy*, VS Abhilash Kumar, Harinath Bellamkonda, Raghuveer Reddy D, Sai Krishna CS, Balaraju \\ Naidu and Shivanshu Mittal \\ Unit of Musculoskeletal Oncology and Pelvic Reconstructive surgery, OMNI Hospital and American Oncology Institute, India
}

Submission: February 09, 2017; Published: February 27, 2017

"Correspondence Address: Kishore B Reddy, Unit of Musculoskeletal Oncology and Pelvic Reconstructive surgery, OMNI Hospital and American Oncology Institute, Plot no.20,21,22A,22B,22C,23 \& 24, Balaji nagar, Kukatpally, Hyderabad- 500072, India, Phone no: +917569707316; E-mail: kishorebhavanam@yahoo.com

\begin{abstract}
Background: Some cases of bone sarcomas require complete resection of femur to achieve adequate tumour free margins. Total Femoral Endoprosthetic Reconstruction is a salvage procedure. It restores femoral integrity and allows early rehabilitation owing to immediate fixation. The function achieved is far superior when compared to hip disarticulation. We present our experience with reconstruction in such cases using a total femoral prosthesis (TFP). Only a few such case series have been published in the literature.
\end{abstract}

Materials and Methods: 12 patients ( 8 males and 4 females) with a mean age of 25 years (10- 68 years), operated between 2010 and 2016, had a Total Femoral Modular Megaprothesis implanted. The diagnosis included osteogenic sarcoma (7), Ewing's sarcoma (2), chondrosarcoma (1), Malignant Fibrous Histiocytoma (1), and metastasis from Renal cell carcinoma-RCC (1).

Results: After a mean follow up of 36.1 months (min 3 months and max 76 months) functional outcome was assessed using the modified rating system of the Musculoskeletal Tumor Society score, the average of which was 21.9 (73\%) (Table 1). Nine patients had no evidence of disease up to the last follow-up. Two patients had pulmonary metastasis and three patients had local recurrence.

Conclusion: Total femoral endoprosthetic reconstruction is a reliable means of restoring anatomic, oncological and functional result after complete femoral resection and a viable alternative to the mutilating procedures like hip disarticulation.

Keywords: Total femoral prosthesis; Total femoral arthroplasty; Limb salvage

\section{Introduction}

Femur is a common site for primary bone sarcomas. Around $16 \%$ of Ewing's sarcomas, $13 \%$ of chondrosarcomas, $10 \%$ of osteosarcomas develop at this anatomic site [1-3]. Such sarcomas involving the whole or major part of femur or those with skip lesions provide only two options- either hip disarticulation or limb salvage surgery. The limb salvage surgery presents a potential challenge. It involves removal of the entire femur along with the reconstruction of hip and knee joints. It also disrupts the hip abductors. When compared to hip disarticulation, limb salvage surgery is cost effective, and provides a more effective gait $[4,5]$. The advent of newer chemotherapy regimens has increased the frequency of limb salvage procedures. The outcome of such procedures in the lower extremity which allows for weight bearing and useful ambulation has been remarkable. Total femoral replacement is the most extreme salvage technique to serve the purpose [6]. Options for reconstruction following extensive resections include total femoral prostheses (TFP), allografts, and rotationplasty [7]. The use of TFR has increased worldwide owing to its use in revision arthroplasty [8]. We here present our experience of 12 cases of total femoral prosthesis used as a salvage and reconstructive procedure in malignant conditions.

\section{Materials and Methods}

Between 2010 and 2016, 12 patient (8 males and 4 females), within the age range from 10 to 68 years (mean age 25 years) with malignant bone tumours involving part of or the entire femur underwent reconstruction using Total Femoral Modular Mega Prosthesis. The most common diagnosis was osteosarcoma (7 cases). The other diagnoses in our study were Ewing sarcoma (2), RCC Metastasis (1), Malignant fibrous histiocytoma (1) and Chondrosarcoma (1). All patients underwent standard radiographic evaluation for staging (MRI and PET CT whole body). Their disease was staged using Enneking's system. All patients were in stage II except 2 patients who presented with Pulmonary metastasis (State III). The diagnosis was confirmed 


\section{Cancer Therapy \& Oncology International Journal}

by needle biopsy in all patients. Preop chemotherapy was given in all cases of osteosarcoma and Ewing's sarcoma.

\section{Prostheses}

ADLER implants with fixed hinge and metallic bipolar head were used in all cases, made of $316 \mathrm{~L}$ Stainless steel in except two where titanium implants were used.

\section{Surgical Technique}

Resection was done by wide excision with margins free of tumor confirmed by biopsy in all cases. Anterolateral approach was used in all the cases. The vastus intermedius muscle was sacrificed and the sciatic nerve (and its branches) was preserved in all. A sleeve of the vastus lateralis and the rectus femoris were preserved to aid in hip flexion in all cases except one (where in rectus was involved in the biopsy scar). Capsule of hip was preserved and repaired. Prolene mesh was used in cases where capsule couldn't be preserved. The proximal tibial cut followed by tibial component implantation was done with PMMA .The remaining vastii were sutured to the illiotibial band. The abductors were sutured to the prostheses. No additional procedures were done in any of the cases. The patients were evaluated at every 6 weeks for the first two visits, every 3 months in the first 2 years and biannually till 5 years. The functional and oncological outcomes were assessed at every visit with physical and radiological examination (X-ray). The mean follow-up is 36.1 months (min 3 months and max 76 months follow-up).

\section{Postoperative Rehabilitation}

Full weight bearing was started from second post-operative day. A walker was used for first two weeks. Limb was maintained in abduction while recumbent to allow the healing of abductors. Quadriceps strengthening was started from $2^{\text {nd }}$ post-operative day and abductor strengthening was started after 6 weeks. Knee immobilizer was used in one patient as a major part of the quadriceps was removed. Patients were advised to avoid movements such as squatting and sitting cross leg for lifetime.

\section{Functional Outcome}

Functional outcome was assessed using the modified rating system of the Musculoskeletal Tumor Society core, the average of which was $21.9(73 \%)$ (Table 1). No limb length discrepancy was observed.

Table 1: ES: Ewing Sarcoma; OGS: Osteogenic Sarcoma; PM: Pulmonary Metastasis; PF: Pathological Fracture; MFH: Malignant Fibrous Histiocytoma; CS: Chondro Sarcoma; RCC: Renal cell carcinoma; LR: Local Recurrence; SI: Superficial Infection; DI: Deep infection; NED: No Evidence of Disease; *at the last follow-up.

\begin{tabular}{|c|c|c|c|c|c|c|}
\hline S. No & Age / Sex & Diagnosis & Last Follow up (months) & Complications & Status at last follow-up & $\begin{array}{c}\text { MSTS Score (0- } \\
\text { 30) }\end{array}$ \\
\hline 1 & $17 \mathrm{yr} / \mathrm{M}$ & ES & 76 months & SI & NED & 21 \\
\hline 2 & $26 \mathrm{yr} / \mathrm{F}$ & $\mathrm{OGS}+\mathrm{PM}$ & 39 months & LR & $\begin{array}{l}\text { Recurrent PM \& death } \\
\text { of PM }\end{array}$ & $18^{*}$ \\
\hline 3 & $16 \mathrm{yr} / \mathrm{M}$ & ES & 48 months & Nil & NED & 22 \\
\hline 4 & $28 \mathrm{yr} / \mathrm{M}$ & $\mathrm{OGS}+\mathrm{PF}$ & 53 months & Nil & NED & 23 \\
\hline 5 & $25 \mathrm{yr} / \mathrm{M}$ & MFH & 48 months & LR,DI & NED & 23 \\
\hline 6 & $17 \mathrm{yr} / \mathrm{M}$ & OGS & 47 months & Nil & NED & 22 \\
\hline 7 & $50 \mathrm{yr} / \mathrm{F}$ & CS & 18 months & SI & LR & 24 \\
\hline 8 & $17 \mathrm{yr} / \mathrm{F}$ & $\mathrm{OGS}+\mathrm{PM}$ & 19 months & $\mathrm{Nil}$ & Death of PM & 23 \\
\hline 9 & $10 \mathrm{yr} / \mathrm{M}$ & OGS & 47 months & Knee Stiffness & NED & 22 \\
\hline 10 & $68 \mathrm{yr} / \mathrm{M}$ & RCC metastasis & 30 months & SI & NED & 23 \\
\hline 11 & $13 \mathrm{yr} / \mathrm{F}$ & OGS & 6 months & Nil & NED & 21 \\
\hline 12 & $15 \mathrm{yr} / \mathrm{M}$ & OGS & 3 months & Nil & NED & 23 \\
\hline
\end{tabular}

\section{Complications}

Three patients had superficial infection which was resolved with wound debridement and IV antibiotics. No hip dislocation observed. There were no mechanical complications in our study such as loosening of tibial component, patella malt racking, and limb length discrepancy. No prosthetic revision was done. Three patients had local recurrence. One patient had a local recurrence at 18 months post-surgery and was advised surgery but lost follow up. Another patient with local recurrence at 12 months post-surgery was treated with local excision and localized radiotherapy. He developed wound dehiscence and then deep infection and was subsequently managed with debridement and biodegradable antibiotic loaded bone cement beads without implant removal. Another patient developed local recurrence 3 times following local excisions and was subsequently treated with hip disarticulation. She died after 39 months post-surgery due to pulmonary metastasis. Another patient died of Pulmonary Metastasis at 19 months post-surgery (Figures $1 \& 2$ ). 


\section{Cancer Therapy \& Oncology International Journal}
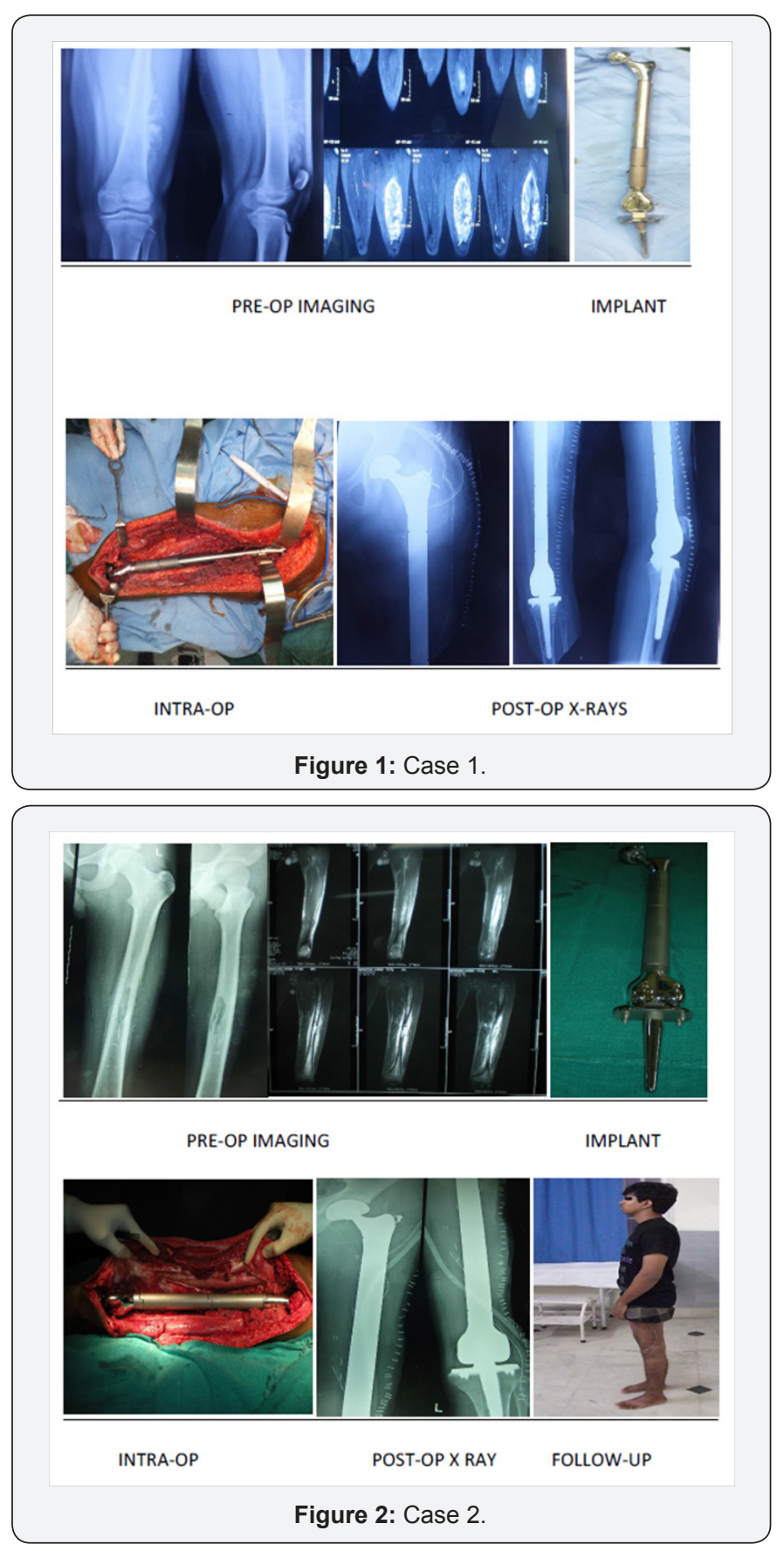

\section{Discussion}

Buchanan was the first to perform a total femur replacement in 1952, and reported a second case in 1965, using a custommade vitallium endoprosthesis, with a good functional result at 6 months [9]. Most patients with sarcomas of the femur extending through a major part or whole of it had an amputation done in the past which resulted in poor functional outcome. The use of improvised imaging and surgical techniques, newer and effective chemotherapy regimens, and advances in prosthesis design and biomaterials have all played a part in increasing the use and outcome of limb salvage surgery. It, however, should not compromise the survival of the patient while ensuring near- normal function as soon as possible $[10,11]$. While the indications for a total femoral prosthesis are extremely limited and highly individual, there is an increase in the number of patients in whom such prosthesis might offer an alternative to amputation (hip disarticulation). Total femoral replacement is mandatory in skip lesions or when there is a massive intramedullary extension if limb salvage is planned. Osteoarticular Allograft replacement has disadvantages:

i. Delayed weight-bearing for at least one year until revascularization of the graft;

ii. Degeneration of articular cartilage; and

iii. Frequent recurrence of the fracture on weight-bearing.

Allo-Prosthetic Composites have disadvantages of increased infection and nonunion (3.7-11\%) [12-15]. Breakage of prosthesis was not encountered in our study, compared to other reports that quote as high as $1-4 \%$ [16]. As expected, there is a certain limitation of movement at the hip and knee and some amount of limp due to abductor insufficiency. Advantages of this method are early functional recovery rate with 70\% MSTS score reported in a study by T. W. R. Briggs et al. [17], relatively low complication rate and a high level of emotional acceptance. The knee functions well postoperatively while the bipolar hip is easier to insert and more stable than a conventional acetabular cup.

\section{Conclusion}

This study presents the total femoral modular mega prosthesis as a viable option for limb reconstruction with reasonably good function of limb. The success of this type of surgery depends on careful patient selection, meticulous surgical technique and better prosthetic design performed in a special center. We conclude that, in selected cases, the total femoral prosthesis offers a realistic alternative to the mutilating procedure of amputation (hip disarticulation).

\section{Reference}

1. Unni KK (1996) Ewing tumor. In: Unni KK, editor. Dahlin's Bone Tumors. General Aspects and Data on 11,087 Cases. Philadelphia: JB Lippincott 249-61.

2. Unni KK (1996) Chondrosarcoma (primary, secondary, dedifferentiated, and clear cell). In: Unni KK, editor. Dahlin's Bone Tumors. General Aspects and Data on 11,087 Cases. Philadelphia: JB Lippincott 71-108.

3. Unni KK (1996) Osteosarcoma. In: Unni KK, editor. Dahlin's Bone Tumors. General Aspects and Data on 11,087 Cases. Philadelphia: JB Lippincot 143-83.

4. Grimer RJ, Carter SR, Pynsent PB (1997) The cost-effectiveness of limb salvage for bone tumours. J Bone Joint Surg Br 79(4): 558-561.

5. Otis JC, Lane JM, Kroll MA (1985) Energy cost during gait in osteosarcoma patients after resection and knee replacement and after above-knee amputation. J Bone Joint Surg Am 67(4): 606-611.

6. Ahmed AR (2010) Total femur replacement. Arch Orthop Trauma Surg 130(2): 171-176. 


\section{Cancer Therapy \& Oncology International Journal}

7. Ajay Puri, Ashish Gulia, Wai Hoong Chan (2012) Functional and oncologic outcomes after excision of the total femur in primary bone tumors: Results with a low cost total femur prosthesis. Indian J Orthop 46(4): 470-474

8. Ramanathan D, Siqueira MB, Klika AK, Higuera CA, Barsoum WK, et al (2015) Current concepts in total femoral replacement. World J Orthop 6(11): 919-926.

9. Buchanan J (1965) Total femur and knee joint replacement with a vitallium prosthesis. Bull Hosp Joint Dis 26: 21-34.

10. Mankin HJ, Hornicek FJ, Harris M (2005) Total femur replacement procedures in tumor treatment. Clin Orthop Relat Res 438: 60-64.

11. Sewell MD, Spiegelberg BG, Hanna SA, Aston WJ, Bartlett W, et al. (2009) Total femoral endoprosthetic replacement following excision of bone tumours. J Bone Joint Surg Br 91:1513-1520.

12. Blunn GW, Wait ME, Lilley P, Walker PS (1991) The reactions of tissues to titanium wear generated from massive segmental bone defect prosthesis. In: Brown KLB (ed) Complications of limb salvage. Prevention, management and outcome. Montreal, ISOLS, pp 429-432
13. Schindler OS, Cannon SR, Briggs TW, Blunn GW (1998) Use of expandable total femoral prosthesis in children with malignant bone tumors. Clin Orthop Rel Res 357: 157-170.

14. Scholz J, Dupka M, Rottger K (1991) Metal-cancellous bone femoral component and total femoral endoprosthesis for surgical treatment of malignant tumors. Biomed Tech (Berl) 36(12): 320-324.

15. Mankin HJ, Gebhardt MC, Jennings LC, Springfield DS, Tomford WW (1996) Long term results of allograft replacement in the treatment of bone tumors. Clin Orthop 324: 86-97.

16. Unwin PS, Cannon SR, Grimer RJ (1996) Aseptic loosening in cemented custom mega prosthesis for malignant bone tumors of lower limb. J Bone Joint Surg [Br] 78: 5-13.

17. MD Sewell, BGI Spiegelberg, SA Hanna, WJS Aston, W Bartlett, et al. (2009) Total femoral endoprosthetic replacement following excision of bone tumours. JBJS 91(11)

\section{Your next submission with Juniper Publishers will reach you the below assets}

- Quality Editorial service

- Swift Peer Review

- Reprints availability

- E-prints Service

- Manuscript Podcast for convenient understanding

- Global attainment for your research

- Manuscript accessibility in different formats

( Pdf, E-pub, Full Text, Audio)

- Unceasing customer service

Track the below URL for one-step submission https://juniperpublishers.com/online-submission.php 